\title{
Contribution of specific diseases and injuries to changes in health adjusted life expectancy in 187 countries from 1990 to 2013: retrospective observational study
}

\author{
He Chen, ${ }^{1}$ Gong Chen, ${ }^{2}$ Xiaoying Zheng, ${ }^{2 *}$ Yan Guo ${ }^{3 *}$
}

${ }^{1}$ Department of Global Health, School of Public Health, Peking University, Beijing, 100191 ,

China

${ }^{2}$ Institute of Population

Research/APEC Health Science

Academy, Peking University,

Beijing, 100871, China

${ }^{3}$ Department of Health Policy and Administration, School of

Public Health, Peking University, Beijing 100191, China

*Contributed equally

Correspondence to: X Zheng

xzheng@pku.edu.cn

(ORCID 0000-0003-1966-044X)

or Y Guo

guoyan@bjmu.edu.cn

(ORCID 0000-0003-1609-3224)

Additional material is published online only. To view please visit the journal online.

Cite this as: $B M / 2019 ; 364: 1969$ http://dx.doi.org/10.1136/bmj.l969

Accepted: 26 February 2019

\section{ABSTRACT}

OBJECTIVE

To quantify and compare the contribution of 306 diseases and injuries to the changes in health adjusted life expectancy at birth $\left(\mathrm{HALE}_{0}\right)$ between 1990 and 2013.

\section{DESIGN}

Retrospective demographic analysis based on aggregated data and using life table technique, Sullivan method, and decomposition method for differences in health expectancy.

\section{SETTING}

The globe, 21 regions, and 187 countries, covered in the Global Burden of Disease Study (GBD) 2013.

\section{MAIN OUTCOME MEASURES}

Cause specific contribution to changes in $\mathrm{HALE}_{0}$ between 1990 and 2013 in terms of mortality effect, disability effect, and total effect.

\section{RESULTS}

Between 1990 and 2013, global HALE increased by 5.31 years for males and 5.73 years for females. The cross national Gini coefficient of $\mathrm{HALE}_{0}$ for both sexes combined decreased by $15.22 \%$ from 0.0736 to 0.0624 . HALE $_{0}$ declined in 11 countries during the period, predominantly owing to HIV/AIDS except in Belize, Belarus, and Paraguay. Controlling communicable, maternal, neonatal, and nutritional diseases accounted for $56.47 \%$ (3.10 years) of changes in HALE for both sexes combined, followed by non-communicable diseases (30.05\%; 1.65 years) and injuries (13.67\%; 0.75 years). Globally, HIV/

\section{WHAT IS ALREADY KNOWN ON THIS TOPIC}

Although previous studies have estimated temporal changes in health adjusted life expectancy at birth (HALE $)$ worldwide, little is known about the role of specific causes

The only two studies on this subject were conducted in Australia and did analyses at disease group level or for selected diseases

According to the epidemiological transition theory, the drivers of population health improvement vary between countries at different stages of epidemiological transition

\section{WHAT THIS STUDY ADDS}

Better control of communicable, maternal, neonatal, and nutritional diseases contributed the most to the global increase of 5.49 years in $\mathrm{HALE}_{0}$ between 1990 and 2013

Cross national inequality in $\mathrm{HALE}_{0}$ decreased by $15.22 \%$ between 1990 and 2013, and $11 / 187$ countries saw a decline in $\mathrm{HALE}_{0}$, mainly due to HIV/AIDS

Diabetes, primary headache with medication overuse, and depressive disorders were the most important negative factors and mainly or only affect $H A L E_{0}$ changes through disability

AIDS caused the biggest reduction in $\operatorname{HALE}_{0}(-0.28$ years) and mainly afflicted residents in southern ( -7.86 years), western ( -1.53 years), and eastern $(-1.38$ years $)$ sub-Saharan Africa. Diabetes had the second biggest negative total effect on changes in $\operatorname{HALE}_{0}$ ( -0.12 years), which was quite widespread across regions. Despite their positive total effect in high income regions, such non-communicable diseases as ischaemic heart disease, cerebrovascular disease, and hypertensive heart disease had a negative total effect in many low and middle income regions. Mortality reduction was the predominant driver (93.62\%; 5.14 years) for improvement in $\mathrm{HALE}_{0}$, accompanied by an increase of 0.80 years in life expectancy lived with disability at birth. Only $44(27 \%)$ of 163 causes at level 3 in the GBD cause hierarchy influenced changes in $\mathrm{HALE}_{0}$, mainly or only through disability.

\section{CONCLUSIONS}

Between 1990 and 2013, the globe made achievements in not only promoting population health as a whole but reducing health inequality between countries. This study pinpoints the priority diseases and injuries for altering the declining health trend in 11 countries, for curbing the epidemic of non-communicable diseases in low and middle income countries, and for promoting compression of morbidity worldwide. The detailed country specific decomposition results of effects of diseases and injuries on change in population health will further facilitate the development of national health policies.

\section{Introduction}

Health adjusted life expectancy (HALE) refers to the equivalent number of years in full health that an individual at a given age can expect to live if exposed to age specific mortality and health status (morbidity) conditions that prevail today. ${ }^{1}$ HALE is a useful summary measure to monitor trends in population health and analyse health inequalities

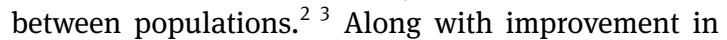
living standards, promotion of education, advances in medical technology, and implementation of public health interventions, HALE has made progress as a whole in the past two decades, with significant disparities across countries. ${ }^{45}$ However, we still have limited knowledge about the contributions of specific diseases and injuries to the changes in HALE during this period.

HALE has several advantages as a summary measure of population health. Two broad families of such measures exist: health expectancies, such as HALE and disability-free life expectancy, ${ }^{256}$ and health 
gaps, such as disability adjusted life years. ${ }^{5}$ The first focuses on life expectancies in full health, using a weighting scheme to adjust life expectancy with nonfatal health states; the second focuses on the difference between actual health and some norms for population health. ${ }^{7}$ As an indicator of health expectancies, HALE has at least the following advantages over health gap indicators. Firstly, based on a life table technique and the Sullivan method, HALE is exempt from the influence of population size and age structure. ${ }^{8} 9$ Secondly, it does not need to set a goal for population heath, such as optimal life expectancy, and thus avoids the potential bias caused by setting such goals. ${ }^{10}$ Additionally, compared with other indicators of health expectancies, the merits of analysing HALE using data from the Global Burden of Disease Study (GBD) are evident. The disability weights scheme of the GBD enables HALE to incorporate a wide range of health states taking account of severity, ${ }^{11}$ rather than using an arbitrary disability threshold like the dichotomous weights (zero or one) used in disabilityfree life expectancy. Furthermore, the GBD data have good cross national comparability and are suitable for global health studies. ${ }^{5}$

For decades, no method was available to decompose differences in health expectancy indicators into the contribution of causes of mortality and disability, even though these indicators are widely used to describe differences in population health over time or across populations. ${ }^{3-5} 912$ In recent years, Nusselder and Looman developed a decomposition method for partitioning differences in health expectancy indicators into the additive contributions of causes. ${ }^{13}$ Considering the advantages of HALE discussed above, decomposition of changes in HALE over time into the contributions of diseases and injuries has the potential to help researchers and policy makers to better understand the changes in population health, to identify health policy priorities, and to provide more evidence on epidemiological transition theory. However, only two studies in Australia have been conducted on the subject, and they used analyses at disease group level or for selected diseases. ${ }^{14} 15$ Therefore, this study aimed to decompose the changes in HALE at birth (HALE $)$ from 1990 to 2013 into the contribution of 306 diseases and injuries for the globe, 21 regions, and 187 countries.

\section{Methods \\ Data}

Data drawn from the GBD 2013 include age and sex specific mortality and years lived with disability per person, as well as age, sex, and cause specific proportion of mortality and years lived with disability per person for the globe, 21 regions, and 187 countries for 1990 and 2013. The GBD 2013 made an effort to bring together available epidemiological data by using a coherent measurement framework and standardised estimation methods, which enables comparative health assessment across countries and time points. ${ }^{5}$ The methods for collecting, processing, and producing these data are briefly described below, and the details can be found in the GBD 2013 papers. ${ }^{510} 16$ Mortality, causes of death, and incidence and prevalence of diseases and injuries for each country, age, sex, and year specific group were estimated according to four general principles: identification of all available data sources, such as published studies, vital registration, surveys, and censuses; quality evaluation and bias correction in each data source; consistent statistical estimation; and cross validation analysis to assess model performance. ${ }^{5}$ Disability weights were based on data from 60890 respondents in household surveys conducted in nine countries (Bangladesh, Indonesia, Peru, Tanzania, the USA, Hungary, Italy, Sweden, and the Netherlands) and a web based survey. The surveys used paired comparison questions: respondents were asked to choose a healthier one from two hypothetical individuals with different and randomly assigned health states. ${ }^{16}$ Then, using a statistical model developed by Salomon and colleagues, the answers to these questions were translated to disability weights with a scale from 0 (equivalent to no health loss) to 1 (equivalent to death). ${ }^{11}$ Additionally, the GBD 2013 used a Monte Carlo simulation method to deal with the issue of comorbidity and adjust the years lived with disability. ${ }^{16}$

\section{Measurement}

Appendix A shows the full list of 306 diseases and injuries in the first column and their corresponding GBD cause hierarchy structure in the second column. The hierarchy structure, developed from the 9th and 10th revisions of the international statistical classification of diseases and related health problems (ICD), has four levels of classification: three broad families at level 1, 21 groups at level 2, 163 categories at level 3, and 254 subcategories at level 4. ${ }^{10} 17$ Specifically, level 1 comprises communicable, maternal, neonatal, and nutritional disorders; non-communicable diseases; and injuries. Level 2 groups are established for their convenience in epidemiological study or main body systems where the conditions occur. Level 3 categories are single conditions selected considering their frequency, severity, or implication to public health interventions; groups of diseases with some common characteristic; or "others" for unspecified conditions and conditions that cannot be included into other categories appropriately. Some categories at level 3 are further divided into subcategories at level 4. Level 3 is the core classification used for most analyses and presentation in this study, as it allows for sufficient detail for interventions and practices and does not complicate analyses like subcategories at level 4 may do.

Disability in this study refers to any short term or long term health loss, other than death. ${ }^{18}$ The years lived with disability per person from a sequela represents the direct consequences of disease or injury that are not otherwise captured elsewhere in the list of causes; they are equal to the prevalence of the sequela multiplied by the disability weight for the health state associated with that sequela. The years lived with 
disability for a disease or injury are the sum of the years lived with disability for each sequela associated with the disease or injury. The years lived with disability per person for an age interval are the sum of the years lived with disability for each disease or injury within that age interval. $^{19}$

We divided 187 countries into 21 regions on the basis of epidemiological homogeneity and geographical contiguity. ${ }^{17}$ The full list of countries and regions is shown in appendix B.

\section{Statistical analyses}

We used a life table technique, the Sullivan method, and a decomposition method for differences in health expectancy to calculate and decompose changes in $\mathrm{HALE}_{0}$. The analysis process is summarised below; detailed equations are given in appendix $\mathrm{C}$.

On the basis of age and sex specific mortality, we constructed abridged life tables to calculate life expectancies (equations 1-12 in appendix C). We included 20 age groups in life tables: early neonatal, late neonatal, post-neonatal, 5 year age groups from 1-4 years to 75-79 years, and 80 years and older.

To calculate $\mathrm{HALE}_{0}$ with the Sullivan method, the first step is to assess the health status of survivors in each age interval. As defined above, disability in this study refers to any health loss caused by diseases and injuries and is calculated with a weight scheme. The health adjusted person years in each age interval are equal to person years lived in that age interval multiplied by the proportion of person years lived in full health, which is one minus the years lived with disability per person. $\mathrm{HALE}_{0}$ is then the total number of health adjusted person years lived after birth divided by the number of people at birth (equation 13 in appendix C). ${ }^{45}$

The decomposition method was developed by Nusselder and Looman in 2004 to examine the contribution made by causes of death and disability to differences in health expectancy between population groups or time points. ${ }^{13}$ Based on Sullivan method, it is an extension of the decomposition method for life expectancy proposed by Arriaga. ${ }^{20}$ It has been repeatedly used in recent studies to analyse the effect of diseases, injuries, and health related factors (for example, smoking) on the disparities in health expectancy at the same time point or the effect of mortality and disability on changes in health expectancy over time. ${ }^{22}{ }^{23}$ However, it is rarely used to decompose the contribution of diseases and injuries to changes in health expectancy over time, owing to data limitations and other factors.

The decomposition process includes four steps. (1) The changes in $\mathrm{HALE}_{0}$ between 1990 and 2013 are decomposed into effects of mortality and disability (equations 14-21 in appendix C). The mortality effect is the changes in $\mathrm{HALE}_{0}$ that would occur if only mortality rates were to change; the disability effect is the changes in $\mathrm{HALE}_{0}$ that would occur if only the proportion of person years lived with disability were to change. (2) The mortality effect is further decomposed by age and cause (equations 22-30 in appendix C). The mortality effect in age interval $(x, x+n)$ is the sum of direct, indirect, and interaction effects of mortality changes in that age interval on the changes in $\mathrm{HALE}_{0}$. To estimate mortality effect by cause, we make an assumption that the contribution of cause $\mathrm{k}$ to changes in life expectancy at birth is proportional to its contribution to the mortality changes in age groups. (3) The disability effect is further decomposed by age and cause (equations 31-36 in appendix C), which is straightforward with age, sex, and cause specific proportions of the years lived with disability per person as key inputs. (4) The mortality effect and disability effect attributable to cause $\mathrm{k}$ are summed up to obtain the total effect for cause $\mathrm{k}$ (equation 37 in appendix C). A positive (negative) value, $\mathrm{Q}$, of mortality or disability effect for cause $\mathrm{k}$ indicates that the mortality or disability brought about by cause $\mathrm{k}$ decreases (increases) between 1990 and 2013, which improves (reduces) HALE $_{0}$ by $\mid$ 미 years during the period.

Furthermore, we used the Gini coefficient to measure inequality in $\mathrm{HALE}_{0}$ between countries. The Gini coefficient is defined as the ratio of the area between the diagonal and the Lorenz curve and the area of the whole triangle under the diagonal. The Gini coefficient ranges from 0 to 1 , with higher values indicating greater inequality. ${ }^{24}$

We used Stata MP (version 14.0) for all analyses. Appendix B provides brief decomposition results for 21 regions and 187 countries. Both the statistical code and the detailed region or country specific decomposition results for 306 diseases and injuries are available on request.

\section{Patient and public involvement}

This study used secondary data from the GBD 2013. No patients were involved in collecting the data or determining the research question, outcome measures, or study design. There are no plans to involve patients in the dissemination of research findings.

\section{Results}

Changes in $\mathrm{HALE}_{0}$

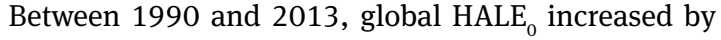
5.49 years for both sexes combined, 5.31 years for males, and 5.73 years for females. The life expectancy lived with disability at birth, which is the difference between life expectancy at birth and HALE ${ }_{0}$, increased by 0.80 years for both sexes combined, 0.63 years for males, and 1.01 years for females (table 1). The percentage of $\mathrm{HALE}_{0}$ in life expectancy at birth increased slightly from $87.17 \%$ (56.79/65.15 years) to $87.17 \%$ (62.28/71.45 years) for both sexes combined, with an increase from $87.93 \%$ to $88.06 \%$ for males and a decrease from $86.44 \%$ to $86.31 \%$ for females.

The changes in HALE $_{0}$ varied substantially across countries (fig 1 and fig 2; see results in appendix B). Of 187 countries, 176 (94\%) made improvements in $\mathrm{HALE}_{0}$, with the biggest increases in Nicaragua (14.65 years), Cambodia (13.93 years), Ethiopia (13.55 years), Niger (13.38 years), and Lebanon (12.26 


\begin{tabular}{|c|c|c|c|c|c|c|c|c|}
\hline \multirow[b]{2}{*}{ Parameter } & \multicolumn{4}{|l|}{ Male } & \multicolumn{4}{|c|}{ Female } \\
\hline & $\mathrm{LE}_{0}$ & $\mathrm{HALE}_{0}$ & LED $_{0}$ & $\mathrm{HALE}_{0} / \mathrm{LE}_{0}(\%)$ & $\mathrm{LE}_{0}$ & HALE $_{0}$ & LED $_{0}$ & $\mathrm{HALE}_{0} / \mathrm{LE}_{0}(\%)$ \\
\hline 1990 & 62.81 & 55.23 & 7.58 & 87.93 & 67.56 & 58.40 & 9.16 & 86.44 \\
\hline 2013 & 68.75 & 60.54 & 8.21 & 88.06 & 74.30 & 64.13 & 10.17 & 86.31 \\
\hline Changes & 5.94 & 5.31 & 0.63 & - & 6.74 & 5.73 & 1.01 & - \\
\hline Mortality effect & 5.94 & 4.90 & 1.04 & - & 6.74 & 5.43 & 1.31 & - \\
\hline Disability effect & 0.00 & 0.41 & -0.41 & - & 0.00 & 0.30 & -0.30 & - \\
\hline
\end{tabular}

years); 11 (5.88\%) countries saw reductions in $\mathrm{HALE}_{0}$, with the biggest decreases in Lesotho ( -11.30 years), Swaziland ( -10.02 years), Zimbabwe ( -5.24 years), South Africa (-3.96 years), and Botswana (-2.04 years). The epidemic of HIV/AIDS was the main reason for the declining $\mathrm{HALE}_{0}$ trend in most of these countries (table 2). Moreover, for countries with $\mathrm{HALE}_{0}$ in 1990 below the median level ( 60.17 years), the baseline $\mathrm{HALE}_{0}$ had a significant negative relation with the changes in $\mathrm{HALE}_{0}$ in the following 23 years (Pearson correlation coefficient $-0.39 ; \mathrm{P}<0.001$ ); however, such a relation did not exist in their counterparts with $\mathrm{HALE}_{0}$ in 1990 equal to or above the median. Additionally, the Gini coefficient of $\mathrm{HALE}_{0}$ across countries declined by $15.22 \%$, from 0.0736 in 1990 to 0.0624 in 2013.

Total effect of causes on changes in $\mathrm{HALE}_{0}$ From 1990 to 2013, better control of communicable, maternal, neonatal, and nutritional diseases contributed the most to changes in $\operatorname{HALE}_{0}$ (56.47\%; 3.10 years) for both sexes combined, followed by control of non-communicable diseases (30.05\%; 1.65 years) and injuries (13.67\%; 0.75 years) (fig 3; appendix A). Nationally, HALE $_{0}$ in 1990 was negatively related to the total effect of communicable, maternal, neonatal, and nutritional diseases (Pearson correlation coefficient $-0.67 ; \mathrm{P}<0.001)$ and positively related to non-communicable diseases $(0.48 ; \mathrm{P}<0.001)$ but not related to injuries $(-0.02 ; \mathrm{P}=0.76)$. Additionally, among the countries with baseline $\mathrm{HALE}_{0}$ lower than the median level (60.17 years), 30/94 (32\%) had a negative total effect attributed to non-communicable diseases, which was much higher than the proportion in their counterparts $(5 / 93 ; 5 \%)$.

Figure 4 shows the top 10 level 3 causes with a positive total effect on changes in $\mathrm{HALE}_{0}$ at the global level and in 21 regions. Globally, more than $60 \%$ (3.44 years) of improvement in $\mathrm{HALE}_{0}$ was attributed to better control

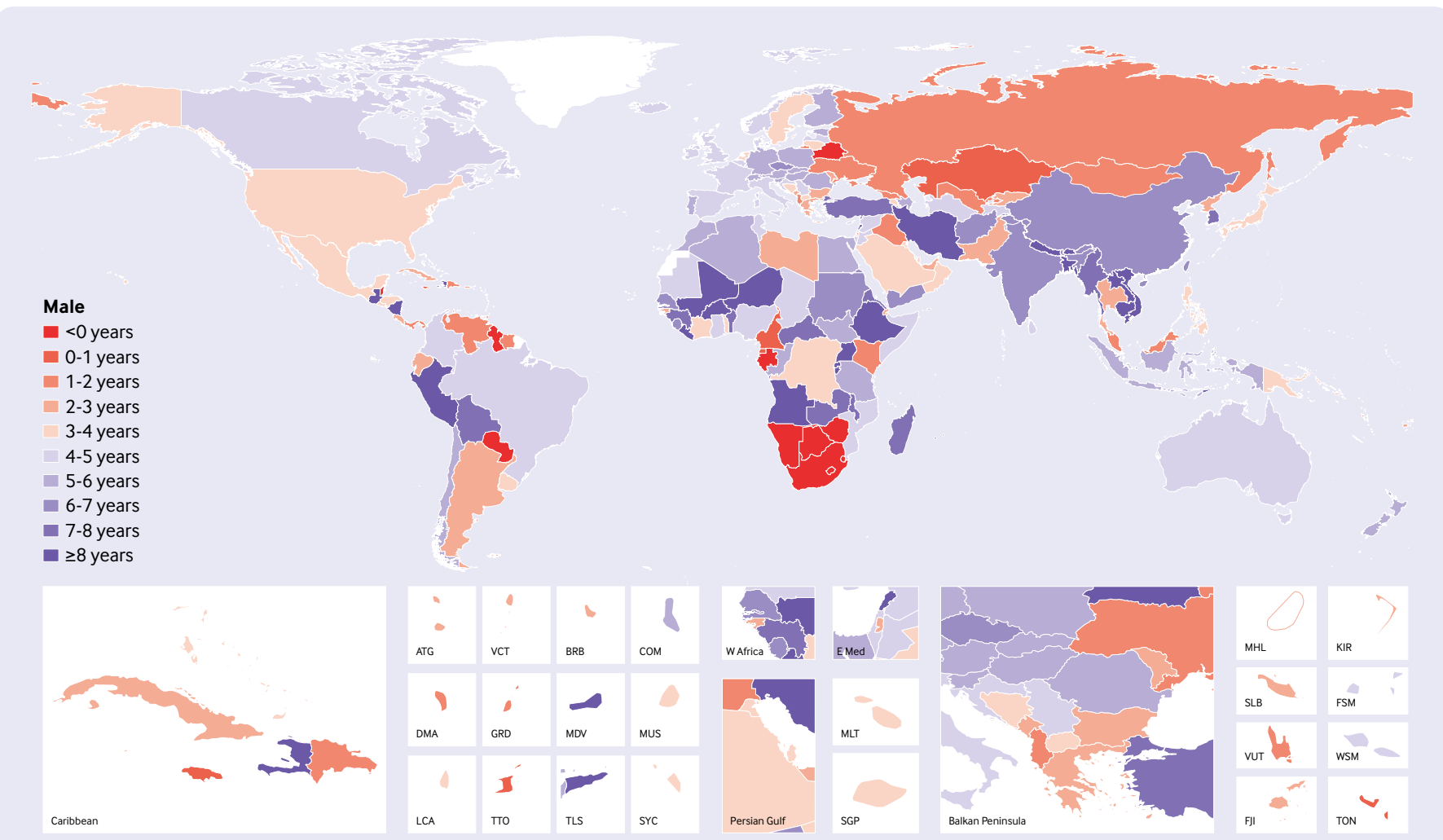

ATG=Antigua and Barbuda, $\mathrm{VCT}=$ Saint Vincent and the Grenadines, $B R B=B$ arbados, $C O M=C o m o r o s, D M A=D o m i n i c a, G R D=G r e n a d a, M D V=M a l d i v e s, M U S=M a u r i t i u s$, LCA=Saint Lucia, TTO=Trinidad and Tobago, TLS=Timor-Leste, SYC=Seychelles, MLT=Malta, SGP=Singapore, MHL=Marshall Islands, KIR=Kiribati, SLB=Solomon Islands, FSM=Federated States of Micronesia, VUT=Vanuatu, WSM=Samoa, FJI=Fiji, TON=Tonga 


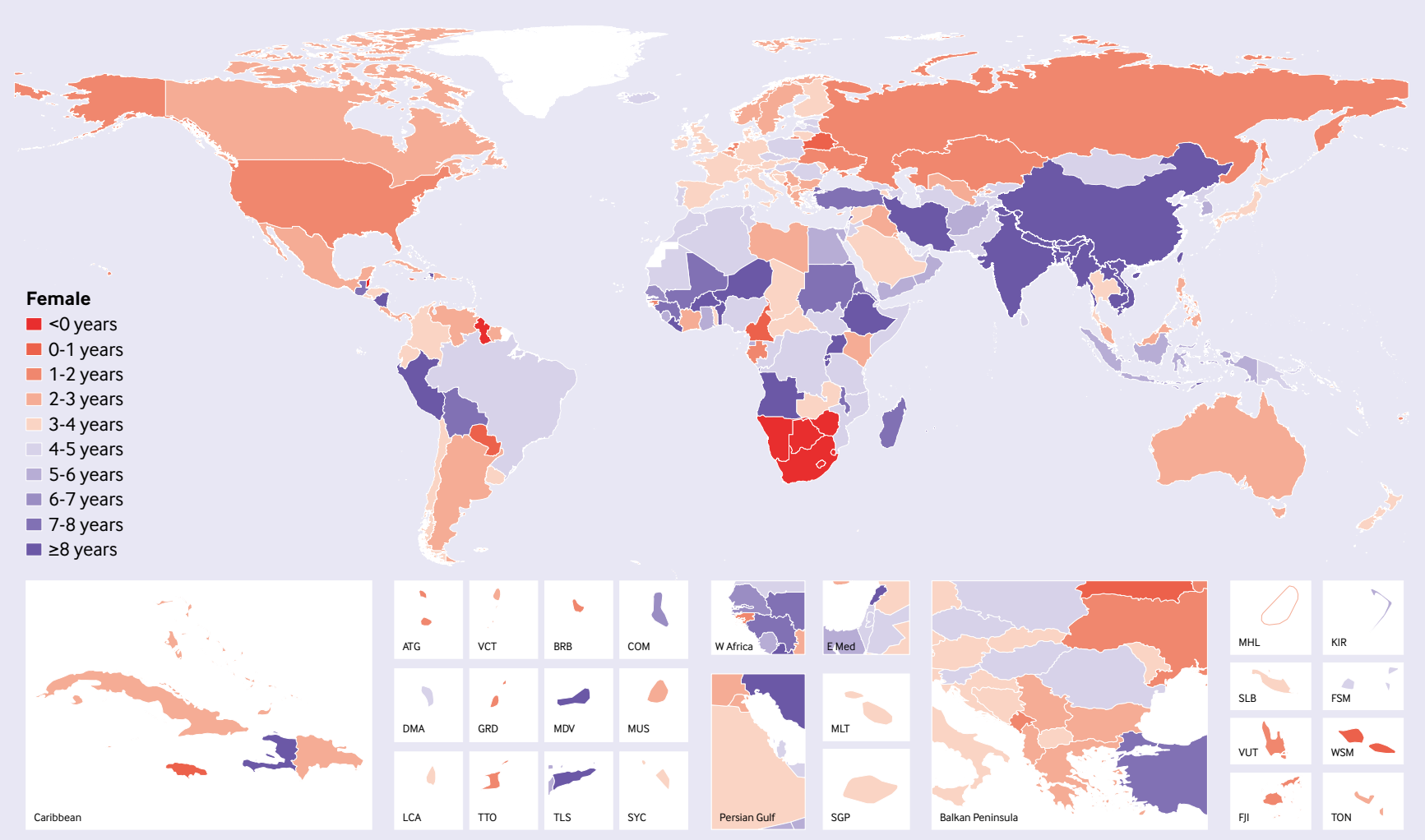

ATG=Antigua and Barbuda, $V C T=S a i n t$ Vincent and the Grenadines, $B R B=B$ arbados, $C O M=C o m o r o s, D M A=D o m i n i c a, ~ G R D=G r e n a d a, M D V=M a l d i v e s, M U S=M a u r i t i u s$, LCA=Saint Lucia, TTO=Trinidad and Tobago, TLS=Timor-Leste, SYC=Seychelles, MLT=Malta, SGP=Singapore, MHL=Marshall Islands, KIR=Kiribati, SLB=Solomon Islands, FSM=Federated States of Micronesia, VUT=Vanuatu, WSM=Samoa, FJI=Fiji, TON=Tonga

Fig 2 | Changes in health adjusted life expectancy at birth $\left(\mathrm{HALE}_{0}\right)$ in females between 1990 and 2013 for 187 countries

of the following 10 diseases: diarrhoea (total effect was 0.69 years for both sexes), lower respiratory infections (0.67 years), ischaemic heart disease (0.38 years), tuberculosis ( 0.35 years), preterm birth complications
(0.34 years), cerebrovascular disease (0.32 years), chronic obstructive pulmonary disease ( 0.23 years), measles ( 0.20 years), iron deficiency anaemia ( 0.15 years), and tetanus (0.13 years). The roles played

\begin{tabular}{|c|c|c|c|c|c|c|}
\hline \multirow[b]{2}{*}{ Country } & \multirow{2}{*}{$\begin{array}{l}\text { HALE }_{0} \\
\text { decreases }\end{array}$} & \multicolumn{5}{|c|}{ Five leading causes of decreases in $\mathrm{HALE}_{0}$ and their total effects } \\
\hline & & 1 & 2 & 3 & 4 & 5 \\
\hline Lesotho & -11.30 & HIV/AIDS (-8.28) & Tuberculosis $(-1.10)$ & $\begin{array}{l}\text { Lower respiratory } \\
\text { infections }(-0.58)\end{array}$ & $\begin{array}{l}\text { Interpersonal violence } \\
(-0.43)\end{array}$ & Road injuries (-0.24) \\
\hline Swaziland & -10.02 & HIV/AIDS (-8.33) & Tuberculosis $(-0.53)$ & $\begin{array}{l}\text { Lower respiratory } \\
\text { infections }(-0.48)\end{array}$ & Road injuries (-0.26) & Self harm $(-0.18)$ \\
\hline Zimbabwe & -5.24 & HIV/AIDS (-6.23) & $\begin{array}{l}\text { Diarrhoeal diseases } \\
(-0.47)\end{array}$ & Tuberculosis $(-0.33)$ & $\begin{array}{l}\text { Lower respiratory } \\
\text { infections }(-0.32)\end{array}$ & $\begin{array}{l}\text { Neonatal encephalopathy due to birth } \\
\text { asphyxia and trauma }(-0.16)\end{array}$ \\
\hline South Africa & -3.96 & HIV/AIDS (-8.56) & Self harm $(-0.10)$ & Road injuries (-0.09) & $\begin{array}{l}\text { Exposure to mechanical } \\
\text { forces }(-0.08)\end{array}$ & Interpersonal violence $(-0.08)$ \\
\hline Botswana & -2.04 & HIV/AIDS (-6.04) & $\begin{array}{l}\text { Interpersonal violence } \\
(-0.19)\end{array}$ & Road injuries (-0.07) & Self harm $(-0.06)$ & Drug use disorders (-0.04) \\
\hline Namibia & -1.53 & HIV/AIDS (-3.56) & Diabetes $(-0.12)$ & $\begin{array}{l}\text { Interpersonal violence } \\
(-0.11)\end{array}$ & Self harm $(-0.10)$ & Road injuries (-0.08) \\
\hline Belize & -1.36 & Diabetes mellitus (-0.64) & HIV/AIDS (-0.34) & $\begin{array}{l}\text { Interpersonal violence } \\
(-0.24)\end{array}$ & $\begin{array}{l}\text { Chronic kidney disease } \\
(-0.17)\end{array}$ & Prostate cancer $(-0.16)$ \\
\hline Gabon & -1.11 & HIV/AIDS (-2.98) & Road injuries (-0.10) & $\begin{array}{l}\text { Diabetes mellitus } \\
(-0.08)\end{array}$ & Self harm $(-0.06)$ & Chronic kidney disease $(-0.06)$ \\
\hline Guyana & -0.51 & HIV/AIDS (-0.75) & $\begin{array}{l}\text { Diabetes mellitus } \\
(-0.48)\end{array}$ & Road injuries (-0.15) & $\begin{array}{l}\text { Chronic kidney disease } \\
(-0.14)\end{array}$ & Congenital anomalies $(-0.13)$ \\
\hline Belarus & -0.19 & $\begin{array}{l}\text { Ischaemic heart disease } \\
(-0.54)\end{array}$ & Self harm $(-0.22)$ & $\begin{array}{l}\text { Cirrhosis due to } \\
\text { hepatitis C }(-0.11)\end{array}$ & $\begin{array}{l}\text { Cardiomyopathy and } \\
\text { myocarditis }(-0.09)\end{array}$ & $\begin{array}{l}\text { Primary headache with medication } \\
\text { overuse }(-0.09)\end{array}$ \\
\hline Paraguay & -0.10 & Diabetes mellitus (-0.42) & Road injuries (-0.20) & $\begin{array}{l}\text { Chronic kidney } \\
\text { disease }(-0.20)\end{array}$ & $\begin{array}{l}\text { Tracheal, bronchus, and } \\
\text { lung cancer }(-0.12)\end{array}$ & Interpersonal violence $(-0.09)$ \\
\hline
\end{tabular}




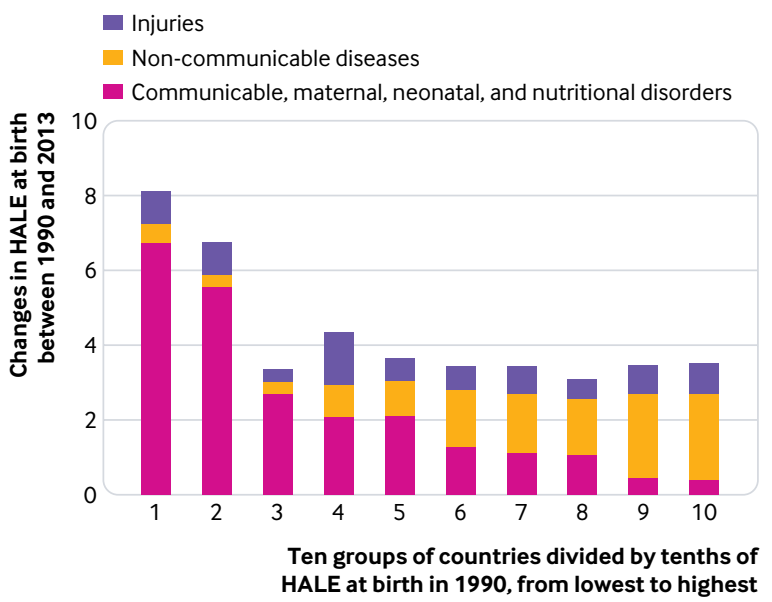

Fig 3 | Contribution of diseases and injuries to the changes in health adjusted life expectancy at birth (HALE) between 1990 and 2013 by tenths of HALE in 1990.

Countries are divided into 10 groups according to tenths of HALE $_{0}$ in 1990. Groups 1 and 10 are groups with lowest and highest $\mathrm{HALE}_{0}$ in 1990, respectively

by diseases and injuries in changes in $\mathrm{HALE}_{0}$ varied substantially across regions. For regions with baseline HALE $_{0}$ between 44 and 55 years (central, eastern, and western sub-Saharan Africa; south Asia; and Oceania), better control of diarrhoeal diseases, lower respiratory infections, malaria, measles, and tuberculosis was the primary driver for improvement in $\mathrm{HALE}_{0}$. As baseline $\mathrm{HALE}_{0}$ increased, the importance of controlling noncommunicable diseases (such as ischaemic heart disease, cerebrovascular diseases, chronic obstructive pulmonary disease, stomach cancer, and lung cancer) and injuries (such as war, natural disaster, traffic injuries, and falling) for improvement in $\mathrm{HALE}_{0}$ increased.

Figure 5 shows the top 10 level 3 causes with a negative total effect on changes in $\mathrm{HALE}_{0}$ at the global level and in 21 regions. Globally, HIV/AIDS caused the biggest reduction in $\mathrm{HALE}_{0}(-0.28$ years) and mainly affected residents in southern $(-7.86$ years), western $(-1.53$ years), and eastern ( -1.38 years) sub-Saharan Africa. With the second biggest negative total effect, diabetes reduced global $\mathrm{HALE}_{0}$ by 0.12 years, ranging from -0.01 years in eastern sub-Saharan Africa to -0.33 years in Oceania. Unlike HIV/AIDS, diabetes had a fairly widespread influence across regions: it was among the top three negative causes in 17 regions and among the top 10 in all the 21 regions. Additionally, although the total effect of such non-communicable diseases as ischaemic heart disease, cerebrovascular disease, and hypertensive heart disease was positive in high income regions (fig 4), the corresponding effect was negative in many low and middle income regions such as central sub-Saharan Africa and south Asia (fig 5).

We observed different transition trajectories of population health between regions with similar baseline health profiles. For example, in 1990, HALE $_{0}$ was 61.43 years in eastern Europe and 62.23 years in central Europe. During the next 23 years, HALE $_{0}$ increased by 4.73 years in central Europe but by only
1.67 years in eastern Europe. Around 70\% (2.12 years) of this difference was caused by ischaemic heart disease, cerebrovascular disease, cardiomyopathy and myocarditis, lower respiratory infections, and HIV/ AIDS.

Effect of mortality and disability on changes in $\mathrm{HALE}_{0}$ Globally, HALE $_{0}$ increased by 5.14 years $(93.62 \%$ of total HALE $_{0}$ changes) as a result of reduced mortality and by 0.36 years as a result of reduced disability. The life expectancy with disability at birth increased by 1.16 years owing to a reduction in mortality and decreased by 0.36 years owing to a reduction in disability (table 1).

For changes in $\mathrm{HALE}_{0}, 94.52 \%$ (2.93/3.10 years) of the total effect of communicable, maternal, neonatal, and nutritional diseases and $62.67 \%$ ( $0.47 / 0.75$ years) of the total effect of injuries came from reductions in mortality. Non-communicable diseases mainly influenced changes in $\mathrm{HALE}_{0}$ through a positive effect on mortality (1.74 years), which was accompanied by a small negative effect of disability ( -0.09 years). Of all the 163 level 3 causes, 22 (13\%) had a higher absolute disability effect than absolute mortality effect-for example, diabetes (mortality effect -0.01 years; disability effect -0.11 years) and iron deficiency anaemia (0.04 years; 0.11 years). Another 22 (13\%) influenced changes in $\mathrm{HALE}_{0}$ only through a disability effect-for example, primary headache with medication overuse ( -0.03 years) and depressive disorders ( -0.02 years).

Partly because of the predominant effect of mortality on changes in $\mathrm{HALE}_{0}$, the top 10 causes of mortality effect were similar to those for the total effect (appendix D). Thus, we describe only the disability effect of causes below.

The top 10 level 3 causes with a positive disability effect on changes in $\mathrm{HALE}_{0}$ included sense organ disease in all the regions; road injuries in all the regions except eastern and western sub-Saharan Africa, south Asia, and Oceania; iron deficiency anaemia and war mainly in regions with low and middle $\mathrm{HALE}_{0}$ in 1990; and falls, oral disorders, exposure to mechanical forces, peptic ulcer disease, and other neurological disorders mainly in regions with middle and high HALE $_{0}$ in 1990 (figure D1 in appendix D).

The top 10 level 3 causes with a negative disability effect on changes in $\mathrm{HALE}_{0}$ included diabetes (except central sub-Saharan Africa), preterm birth complications, and primary headache with medication overuse in all the regions; other musculoskeletal disorders and chronic obstructive pulmonary disease in most regions across different levels of $\mathrm{HALE}_{0}$ in 1990; HIV/AIDS mainly in Africa, Oceania, and eastern Europe; other neonatal disorders mainly in regions with middle and high $\mathrm{HALE}_{0}$ in 1990; and other cardiovascular and circulatory diseases, depressive disorders, and congenital anomalies in some regions without an obvious pattern (figure D2 in appendix D).

Considering the mortality and disability effect together, we found some interesting results. Firstly, 


\begin{tabular}{|c|c|c|c|c|c|c|c|c|c|c|}
\hline \multirow[b]{2}{*}{ Regions } & \multicolumn{10}{|c|}{ Top 10 positive contributors to changes in $\mathrm{HALE}_{0}$ in terms of total effect } \\
\hline & 1 & 2 & 3 & 4 & 5 & 6 & 7 & 8 & 9 & 10 \\
\hline Global & Diarrhoea & LRI & IHD & Tuberculosis & NN preterm & Stroke & COPD & Measles & Iron anaemia & Tetanus \\
\hline Central sub-Saharan Africa & Malaria & LRI & Diarrhoea & Tuberculosis & Measles & Onchocerciasis & Trypano & STD & Cough & Protein malnu \\
\hline Eastern sub-Saharan Africa & Diarrhoea & LRI & Malaria & Measles & Tuberculosis & War & Protein malnu & Meningitis & Iron anaemia & NN preterm \\
\hline Western sub-Saharan Africa & Diarrhoea & Measles & LRI & Malaria & Tuberculosis & Protein malnu & Onchocerciasis & Meningitis & NN preterm & Cough \\
\hline South Asia & Diarrhoea & LRI & Tuberculosis & NN preterm & Iron anaemia & Other NN & Tetanus & COPD & Asthma & Fire sub \\
\hline Oceania & LRI & Diarrhoea & Intestinal inf & Tuberculosis & Measles & Meningitis & Other NN & Malaria & Pulcer & Iron anaemia \\
\hline Southern sub-Saharan Africa & Diarrhoea & IHD & Tuberculosis & War & Other NN & Drugs & Measles & LRI & Protein malnu & Stroke \\
\hline Andean Latin America & War & LRI & Diarrhoea & Nature & Tuberculosis & Protein malnu & NN preterm & Road injuries & Stroke & Mechanic \\
\hline Southeast Asia & War & LRI & Diarrhoea & Tuberculosis & Measles & Iron anaemia & NN preterm & Stroke & Other NN & Tetanus \\
\hline North Africa and Middle East & LRI & Diarrhoea & IHD & Stroke & NN preterm & Nature & Road injuries & Congenital & Other cardio & COPD \\
\hline Central Asia & LRI & Diarrhoea & Road injuries & NN enceph & Falls & Stomach C & Lung C & COPD & Drown & Stroke \\
\hline Caribbean & Diarrhoea & LRI & IHD & Tuberculosis & Stroke & Protein malnu & Meningitis & NN preterm & Iron anaemia & Road injuries \\
\hline Tropical Latin America & IHD & Diarrhoea & Stroke & LRI & NN preterm & Road injuries & COPD & NN enceph & Protein malnu & Chagas \\
\hline East Asia & COPD & LRI & Stroke & NN preterm & Diarrhoea & Drown & Self-harm & Tuberculosis & Stomach C & RHD \\
\hline Eastern Europe & Stroke & Road injuries & IHD & NN enceph & Congenital & Stomach C & Other inj & COPD & Lung $C$ & NN preterm \\
\hline Central Latin America & Diarrhoea & LRI & War & Road injuries & Protein malnu & NN preterm & Stroke & Violence & IHD & NN enceph \\
\hline Central Europe & IHD & Stroke & LRI & Road injuries & Falls & NN preterm & Congenital & COPD & NN enceph & Stomach C \\
\hline Southern Latin America & IHD & Stroke & NN preterm & Lung C & Violence & War & Mechanic & Self-harm & Falls & NN enceph \\
\hline High income North America & IHD & Road injuries & HIV/AIDS & Stroke & Lung $C$ & LRI & Violence & Breast C & Falls & Colorect C \\
\hline Western Europe & IHD & Stroke & Road injuries & Falls & Lung C & Self-harm & Stomach C & COPD & Congenital & LRI \\
\hline Australasia & IHD & Stroke & Road injuries & Lung C & COPD & Falls & Colorect C & Congenital & LRI & Breast C \\
\hline High income Asia-Pacific & Stroke & IHD & Stomach C & Road injuries & LRI & COPD & Asthma & Falls & HTN HD & Congenital \\
\hline
\end{tabular}

\begin{tabular}{|l|l}
\hline Diarrhoea & Diarrhoeal diseases \\
\hline NN preterm & Preterm birth complications \\
\hline Iron anaemia & Iron deficiency anaemia \\
\hline
\end{tabular}

\begin{tabular}{|c|l|}
\hline LRI & Lower respiratory infections \\
\hline Stroke & Cerebrovascular disease \\
\hline Tetanus & Tetanus \\
\hline
\end{tabular}

\begin{tabular}{l|l} 
IHD & Ischaemic heart disease \\
COPD & Chronic obstructive pulmonary disease
\end{tabular}

\begin{tabular}{|c|c|}
\hline Tuberculosis & Tuberculosis \\
\hline Measles & Measles \\
\hline
\end{tabular}

Fig 4 | Top 10 positive contributors to changes in health adjusted life expectancy at birth (HALE $)_{0}$ in terms of total effect at global level and in 21 regions. Regions are ordered according to $\mathrm{HALE}_{0}$ in 1990, from lowest to highest. All diseases and injuries are at level 3. Breast $C=b r e a s t$ cancer; Chagas=Chagas disease; Colorect $\mathrm{C}=$ colon and rectum cancer; Congenital=congenital anomalies; $\mathrm{COPD}=$ chronic obstructive pulmonary disease; Cough=whooping cough; Drugs=drug use disorders; Drown=drowning; Fire sub=fire, heat, and hot substances; HTN HD=hypertensive heart disease; Intestinal inf=intestinal infectious diseases; Lung $C=$ tracheal, bronchus, and lung cancer; Mechanic=exposure to mechanical forces; nature=exposure to forces of nature; $\mathrm{NN}$ enceph=neonatal encephalopathy due to birth asphyxia and trauma; Other inj=other unintentional injuries; Other cardio=other cardiovascular and circulatory diseases; Other NN=other neonatal disorders; Protein malnu=protein-energy malnutrition; P ulcer=peptic ulcer disease; RHD=rheumatic heart disease; $S T D=$ sexually transmitted diseases excluding HIV; Stomach C=stomach cancer; Trypano=African trypanosomiasis; Violence=interpersonal violence; $W a r=$ collective violence and legal intervention

diabetes had a negative disability effect worldwide, yet its negative mortality effect was concentrated in regions with low and middle HALE $\mathrm{H}_{0}$ in 1990. Secondly, preterm birth complications had a positive mortality effect and negative disability effect in almost all countries. The exceptions were a negative mortality effect of preterm birth complications in Zimbabwe, Swaziland, and Vanuatu. Thirdly, compared with that in 1990, a high proportion of countries had a lower mortality from chronic obstructive pulmonary disease $(64.17 \%$; $120 / 187$ countries), cerebrovascular disease (47.06\%; $88 / 187$ countries), and other cardiovascular and circulatory disease $(62.03 \% ; 116 / 187$ countries), yet bore a heavier disability burden from these diseases, in 2013. Some countries made progress in reducing both mortality and disability from these diseases. For example, 56 of 187 countries (such as Vietnam, Brazil, Argentina, Finland, Italy, and Japan) had a positive mortality effect and a small positive disability effect of cerebrovascular disease on changes in $\mathrm{HALE}_{0}$ during the 24 years.

\section{Discussion}

Globally, people lived 5.49 years longer in full health in 2013 than in 1990, which was mainly because of the better control of communicable, maternal, neonatal, and nutritional diseases (3.10 years; $56.47 \%$ ), followed by non-communicable diseases (1.65 years; $30.05 \%)$ and injuries (0.75 years; $13.67 \%)$. The cross national Gini coefficient of HALE 


\begin{tabular}{|c|c|c|c|c|c|c|c|c|c|c|}
\hline \multirow[b]{2}{*}{ Regions } & \multicolumn{10}{|c|}{ Top 10 negative contributors to changes in $\mathrm{HALE}_{0}$ in terms of total effect } \\
\hline & 1 & 2 & 3 & 4 & 5 & 6 & 7 & 8 & 9 & 10 \\
\hline Global & HIV/AIDS & Diabetes & Chr kidney & M headache & Depression & Other MSK & Drugs & ILD & Haemoglo & Alzheimer \\
\hline Central sub-Saharan Africa & HIV/AIDS & Self harm & Cirr hep C & Diabetes & M headache & IHD & Endocrine & HTN HD & Skin & NN sepsis \\
\hline Eastern sub-Saharan Africa & HIV/AIDS & M headache & Back \& neck & Other MSK & Diabetes & Depression & Alzheimer & Prostate $\mathrm{C}$ & Intel dis & Drugs \\
\hline Western sub-Saharan Africa & HIV/AIDS & Diabetes & Road injuries & Stroke & IHD & HTN HD & CMP & Drugs & M headache & Endocrine \\
\hline South Asia & Self harm & Diabetes & Chr kidney & $\mathrm{IHD}$ & HTN HD & M headache & Depression & Road injuries & Other cardio & Other MSK \\
\hline Oceania & Diabetes & HIV/AIDS & Chr kidney & Violence & Liver C & Medical & Animal & Breast C & CMP & Congenital \\
\hline Southern sub-Saharan Africa & HIV/AIDS & Violence & Diabetes & Self harm & Alcohol & Mechanic & Road injuries & Endocrine & Other MSK & M headache \\
\hline Andean Latin America & Other MSK & HIV/AIDS & Diabetes & Cirr hep C & Chr kidney & Alcohol & Congenital & Liver C & Pancreatic C & Prostate C \\
\hline Southeast Asia & Diabetes & HIV/AIDS & Alzheimer & COPD & Migraine & Other MSK & Drugs & M headache & Urinary & Liver C \\
\hline North Africa and Middle East & Diabetes & M headache & Drugs & Liver C & HIV/AIDS & Other MSK & Depression & Self harm & Medical & Endocrine \\
\hline Central Asia & Diabetes & Cirr hep B & HIV/AIDS & Cirr alcohol & M headache & War & Other cardio & Cirr hep C & Other cirr & Pancreatic C \\
\hline Caribbean & Diabetes & Nature & Prostate C & Chr kidney & Liver C & Other MSK & Pancreatic C & HTN HD & Medical & M headache \\
\hline Tropical Latin America & Diabetes & Other MSK & Depression & Prostate C & Alzheimer & Anxiety & Brain C & Endocrine & Colorect C & M headache \\
\hline East Asia & Diabetes & Back \& neck & Chr kidney & ILD & M headache & HIV/AIDS & Lung C & CMP & Other respira & Prostate C \\
\hline Eastern Europe & CMP & HIV/AIDS & M headache & Cirr hep C & Other MSK & Cirr alcohol & Diabetes & Tuberculosis & HTN HD & Cirr hep B \\
\hline Central Latin America & Chr kidney & Diabetes & Other MSK & HIV/AIDS & Prostate C & Alzheimer & M headache & Colorect C & Atrial FF & Brain C \\
\hline Central Europe & M headache & Diabetes & Atrial FF & Back \& neck & Alzheimer & Kidney C & Prostate C & War & Drugs & Inflam bowel \\
\hline Southern Latin America & Other MSK & Pancreatic C & Drugs & COPD & Other inj & HIV/AIDS & Diabetes & M headache & HTN HD & Urinary \\
\hline High income North America & Diabetes & Drugs & Chr kidney & Alzheimer & Back \& neck & M headache & Parkinson & Other MSK & Depression & Cirr hep C \\
\hline Western Europe & Alzheimer & Diabetes & M headache & Other MSK & Atrial FF & Urinary & Multiple sclerosis & Prostate C & Other NN & Diarrhoea \\
\hline Australasia & Diabetes & Other cardio & Atrial FF & Inflam bowel & M headache & Other NN & Other MSK & Chr kidney & Drugs & Liver C \\
\hline High income Asia-Pacific & Diabetes & Back \& neck & Self harm & Other cardio & M headache & Parkinson & Colorect C & Prostate C & Breast C & Other MSK \\
\hline
\end{tabular}

\begin{tabular}{|c|c|}
\hline HIV/AIDS & HIV/AIDS \\
\hline M headache & Primary headache with medication overuse \\
\hline Drugs & Drug use disorders \\
\hline Alzheimer & Alzheimer's disease and other dementias \\
\hline
\end{tabular}

\begin{tabular}{|c|c|c|c|}
\hline Diabetes & Diabetes mellitus & Chr kidney & Chronic kidney disease \\
\hline Depression & Depressive disorders & Other MSK & Other musculoskeletal disorders \\
\hline ILD & Interstitial lung disease and pulmonary sarcoidosis & Haemoglo & Haemoglobinopathies and haemolytic anaemias \\
\hline Prostate C & Prostate cancer & & \\
\hline
\end{tabular}

Fig 5 | Top 10 negative contributors to changes in health adjusted life expectancy at birth (HALE $)_{0}$ in terms of total effect at global level and in 21 regions. Regions are ordered according to $\mathrm{HALE}_{0}$ in 1990, from lowest to highest. All diseases and injuries are at level 3. Alcohol=alcohol use disorders; Animal=animal contact; Anxiety=anxiety disorders; Atrial FF=atrial fibrillation and flutter; Back \& neck=low back and neck pain; Brain $\mathrm{C}=$ brain and nervous system cancer; Breast $\mathrm{C}=$ breast cancer; Cirr alcohol=cirrhosis due to alcohol use; Cirr hep B=cirrhosis due to hepatitis $\mathrm{B}$; Cirr hep $\mathrm{C}=$ cirrhosis due to hepatitis $\mathrm{C}$; $\mathrm{CMP}=$ cardiomyopathy and myocarditis; Colorect $\mathrm{C}=$ colon and rectum cancer; Congenital=congenital anomalies; $\mathrm{COPD}=$ chronic obstructive pulmonary disease; Diarrhoea=diarrhoeal diseases; Endocrine=endocrine, metabolic, blood, and immune disorders; HTN HD=hypertensive heart disease; IHD=ischaemic heart disease; Inflam bowel=inflammatory bowel disease; Intel dis=idiopathic intellectual disability; Kidney $C=$ kidney cancer; Liver $C=$ liver cancer; Lung $C=$ tracheal, bronchus, and lung cancer; Mechanic=exposure to mechanical forces; Medical=adverse effects of medical treatment; Nature=exposure to forces of nature; NN sepsis=neonatal sepsis and other neonatal infections; Other cardio=other cardiovascular and circulatory diseases; Other cirr=cirrhosis due to other causes; Other inj=other unintentional injuries; Other $\mathrm{NN}=$ other neonatal disorders; Other respira=other chronic respiratory diseases; Pancreatic C=pancreatic cancer; Parkinson=Parkinson's disease; Skin=skin and subcutaneous diseases; Stroke=cerebrovascular disease; Urinary=urinary diseases and male infertility; Violence=interpersonal violence; War=collective violence and legal intervention

decreased by $15.22 \%$, indicating an improvement in health equality between countries. $\mathrm{HALE}_{0}$ declined in 11 countries during the period. Between 1990 and 2013, the top 10 positive contributors to changes in global $\mathrm{HALE}_{0}$ were diarrhoea, lower respiratory infections, ischaemic heart disease, tuberculosis, preterm birth complications, cerebrovascular disease, chronic obstructive pulmonary disease, measles, iron deficiency anaemia, and tetanus. The top 10 negative contributors to changes in global $\mathrm{HALE}_{0}$ were HIV/AIDS, diabetes, chronic kidney disease, primary headache with medication overuse, depressive disorders, other musculoskeletal disorders, drug use disorders, interstitial lung disease and pulmonary sarcoidosis, haemoglobinopathies and haemolytic anaemia, and Alzheimer's disease and other dementias. We found a small overlap between high and low income regions in the lists of top contributors to changes in $\mathrm{HALE}_{0}$, especially in the list of positive contributors. Some important positive contributors to changes in $\mathrm{HALE}_{0}$ 
in high income regions were negative contributors in low and middle income countries-for example, cerebrovascular disease.

The slow reduction in disability resulted in a longer life expectancy lived with disability. For most diseases and injuries, a mortality effect was the predominant way of influencing changes in $\mathrm{HALE}_{0}$. Disability related to non-communicable diseases increased, which reduced HALE $_{0}$ by 0.09 years during the 24 years.

\section{Strengths and limitations of study}

Previous studies have estimated temporal changes in $\mathrm{HALE}_{0}$ and briefly analysed the contribution of mortality and disability to changes in $\mathrm{HALE}_{0}{ }^{4}{ }^{5}$ However, none has provided information on the contribution of diseases and injuries to the changes in HALE $_{0}$ for the globe or for specific countries except Australia, ${ }^{14} 15$ despite its importance in assessing and developing health policies. The process of change in HALE $_{0}$ was thus much like a "black box" regarding the roles of disease and injuries. This study is the first to decompose changes in $\mathrm{HALE}_{0}$ into the contributions of specific diseases and injuries for the globe, 21 regions, and 187 countries.

Although the decomposition method for differences in health expectancy has been developed over 10 years, it is mainly used to analyse the cross sectional differences in health expectancy between population groups-for example, with different health behaviours or levels of education. ${ }^{25} 26$ This study extends its application by using the GBD data for two time points, 1990 and 2013, which enables us to analyse the contribution of diseases and injuries to temporal changes in $\mathrm{HALE}_{0}$ worldwide. The decomposition results in this study have at least the following advantages: lack of influence by population size and age structure; no requirement for setting optimal life expectancy; inclusion of a wide range of diseases and injuries, and their disability weight; good global comparability; and ability to quantify the mortality and disability effects of causes on population health. ${ }^{8-11}$ The detailed syntax used in our analyses is available on request, which could be a useful tool for researchers, policy makers, and other stakeholders in future studies.

This study has some limitations related to the Sullivan method and the decomposition method. Firstly, the Sullivan method can produce unbiased and consistent estimation of HALE under an assumption of stationarity, which guarantees that cross sectional data from different cohorts can be used to infer the age specific disability prevalence of a hypothetical cohort. ${ }^{27}$ As a result, for populations that incurred a sudden and significant health event between 1990 and 2013, such as natural disaster or war, the $\mathrm{HALE}_{0}$ estimation should be explained with caution. Secondly, we decomposed changes in $\mathrm{HALE}_{0}$ during 24 years, which possibly overlooked the differences in causes' contributions to population health changes between smaller time intervals, such as 1990-2000 and 200113. ${ }^{5}$ Thirdly, we did not calculate confidence intervals for point estimates of $\operatorname{HALE}_{0}$, changes in $\mathrm{HALE}_{0}$, and the contribution of causes to changes in $\mathrm{HALE}_{0}$. This limits the ability to draw statistical inferences.

Moreover, this study shares the same limitations as the GBD 2013 study in the process of collecting and analysing data on mortality and years lived with disability. These limitations have been discussed in detail elsewhere, ${ }^{510} 16$ and we describe here the limitations that are most likely to have influenced our study. Firstly, although the GBD team makes a great effort to identify and use all available data sources, some important unpublished data sources may be missing. ${ }^{19}$ Secondly, data quality varies across countries. The low quality of data might result in substantial uncertainty in the estimation in many low and middle income countries, such as sub-Saharan African countries. ${ }^{10}$ Thirdly, some shortcomings might reduce the comparability of cause specific mortality and years lived with disability between countries. Considerable national variation exists in coding practices for causes of death. Even medical certification of causes of death has limitations, and global or regional algorithms are needed to redistribute deaths assigned to garbage codes. The physicians responsible for assigning causes of death possibly receive different training in verbal autopsy and use different instruments in practice. ${ }^{10}$ Similarly, in the estimation of cause specific years lived with disability, the data for a sequela are probably collected using different definitions, assays, or instrument items. Fixed effects in the meta-regression were used to deal with these differences. ${ }^{16}$ Fourthly, efforts are made to improve the data comparability over time through, for example, mapping variants of the international classification of diseases. However, some time trends might be affected by changes in diagnostic technology and healthcare accessibility. ${ }^{1028}$ For instance, compared with 2013, causes are more likely to have been under-diagnosed and thus under-reported in 1990 owing to lack of diagnostic techniques such as imaging. Lastly, the information on disability weight was not obtained from a random sample of the world's population. ${ }^{11}$ Omission of some aspects of health states in developing lay language and translation of lay language may have introduced bias into the estimation of disability weight. The respondents are members of the general population, rather than healthcare professionals, and their assessments of severity of health states are subjective. ${ }^{19}$

\section{Comparison with other studies}

Consistent with previous studies, ${ }^{5}$ females experienced greater increases in $\mathrm{HALE}_{0}$ than males did between 1990 and 2013, which was mainly because of the higher total mortality effect for females (5.43 years) than males ( 4.90 years). This study further added that cardiovascular diseases, diarrhoea, lower respiratory and other common infectious diseases, and maternal disorders contributed the most to the advantages of females in mortality effects. On the basis of the previous literature, the following factors could help us 
to understand the sex difference in changes in $\mathrm{HALE}_{0}$ in this period: the substantially increased awareness of cardiovascular diseases in women ${ }^{29}$; reduced household air pollution, especially that resulting from cooking ${ }^{30}{ }^{31}$; improved health system capacity, including routine reproductive healthcare, perinatal healthcare, and obstetric care ${ }^{32}$; and macro factors such as economic development, gender equality, and empowerment of women. ${ }^{30}$

The contribution of non-communicable diseases to changes in HALE $_{0}$ between 1990 and 2013 varied substantially across countries. Firstly, although such non-communicable diseases as ischaemic heart disease and cerebrovascular disease were the main positive contributors to changes in $\mathrm{HALE}_{0}$ in high income countries, their negative impact on population health has been growing in low and middle income countries. ${ }^{33}$ Secondly, our results indicate a moderate and positive relation between $\mathrm{HALE}_{0}$ in 1990 and the total effect of non-communicable diseases on changes in $\mathrm{HALE}_{0}$. However, this is not a simple linear relation, which can be illustrated by the role of non-communicable diseases in the different epidemiological transition trajectories between eastern and central Europe. ${ }^{34}$ Thirdly, considering non-communicable diseases are a cluster of 184 diseases in this study, the explanation for the cross national disparities in their total effect is undoubtedly complex. ${ }^{35}$ According to the literature review by Ezzati and Riboli, ${ }^{36}$ the trends in the prevalence of behavioural risk factors (for example, tobacco use, excessive alcohol consumption, poor diet, and physical inactivity) and intermediate phenotypes (for example, hypertension, hypercholesterolaemia, and obesity) are important predictors for the burden of non-communicable diseases. In some less developed countries, infectious diseases, malnutrition, and other diseases of poverty could also contribute to the burden of non-communicable diseases, such as heart disease caused by rheumatic fever. ${ }^{35}$ Fourthly, and methodologically, as this study concerns the changes in $\mathrm{HALE}_{0}$, those countries in which the main disease burden did not result from non-communicable diseases at baseline potentially had a narrower space for health improvement related to these diseases during the next 23 years than did their counterparts.

Unlike high income countries, low income countries obtained the most improvement in population health from the better control of communicable, maternal, neonatal, and nutritional disorders. For example, neglected tropical diseases and malaria were the highest or second highest positive contributor to changes in $\mathrm{HALE}_{0}$ in central (2.09 years), eastern (1.32 years), and western (1.15 years) sub-Saharan Africa. This achievement is a result of multiple factors, such as economic development, improvement in public health, and international health assistance. ${ }^{37}{ }^{38}$ Nevertheless, despite such achievement, communicable, maternal, neonatal, and nutritional disorders are still the major disease burden for low income countries and need more effort in the future. ${ }^{5}$
Another contribution of this study is to quantify how individual diseases and injuries influence changes in population health through mortality and disability. Consistent with previous studies, ${ }^{4} 5$ reduction in mortality explained more than $90 \%$ (5.14/5.49 years) of changes in $\mathrm{HALE}_{0}$ during the 24 years. As the pace of mortality reduction was much faster than that of disability reduction, males and females lived 0.63 years and 1.01 years longer with disability from 1990 to 2013, respectively, which increased the need for long term care and healthcare. ${ }^{39}$ More attention should be paid to reducing disability. Our results provide some insights into this. Firstly, diabetes, primary headache with medication overuse, and depressive disorders are among the 10 level 3 causes with the biggest negative

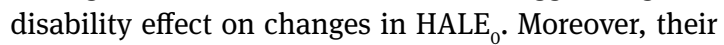
disability effect is the only or main way of influencing $\mathrm{HALE}_{0}$. Reduction in the prevalence and incidence of these causes is expected to reduce the number of years lived with disability if other conditions remain unchanged. Secondly, lessons should be learnt from the countries that obtained both positive mortality and disability effects from chronic obstructive pulmonary disease, cerebrovascular disease, and other cardiovascular and circulatory disease. ${ }^{4041}$

\section{Conclusions and policy implications}

Between 1990 and 2013, the globe made achievements in not only promoting population health as a whole but reducing health inequality between countries, in terms of HALE $_{0}$. However, 11 countries, nearly $6 \%$ of countries studied, saw a decline in population health during the same period. Our results clearly show that effective policies against HIV/AIDS will have a decisive role in altering the declining health trends in these countries, except Belize, Belarus, and Paraguay. Ending the epidemic of HIV/AIDS is a key target of the sustainable development goals. Measures such as mass media campaigns, interventions for sex workers, treatment of sexually transmitted infections, antiretroviral therapy, and improvement in gender equality, might help to relieve the burden of HIV/AIDS. ${ }^{42}{ }^{43}$ Moreover, diabetes and HIV/AIDS in Belize, ischaemic heart disease and self harm in Belarus, and diabetes and road injuries in Paraguay should be considered as priorities for health policies in these countries.

Among the countries with baseline population health below the median level, nearly one third bore a heavier burden from non-communicable diseases than they did 23 years ago. For example, $\mathrm{HALE}_{0}$ in Ghana was shortened by 0.85 years owing to increasing ischaemic heart disease and cerebrovascular disease, which was greater than the increase in $\mathrm{HALE}_{0}$ due to better control of tuberculosis and meningitis (0.80 years). Appendix B shows the countries with negative contributions of non-communicable diseases to changes in $\mathrm{HALE}_{0}$. Along with demographic and epidemiological transition, these countries are becoming increasingly important for promoting implementation of the World Health Organization's Global Action Plan for the prevention and control of non-communicable diseases 
2013-2020 and meeting the non-communicable diseases (target 3.4) and related targets of the 2030 Agenda for Sustainable Development.

Our results further indicate that $\mathrm{HALE}_{0}$ loss caused by the following non-communicable diseases was highest between 1990 and 2013 in developing countries and should be considered as a priority in health policies: diabetes mellitus, chronic kidney disease, primary headache with medication overuse, depressive disorders, other musculoskeletal disorders, low back and neck pain, and Alzheimer's disease and other dementias. WHO and other stakeholders have recommended "best buys" or other measures against these non-communicable diseases, ${ }^{44-49}$ which could serve as a basis for developing policies. Moreover, less developed and developing countries may need international health aid to combat non-communicable diseases-for example, by strengthening health system capacity and making national disease prevention and control plans. Unfortunately, despite their importance to global health, non-communicable diseases received only $1.2 \%$ (4.2 billion) of global development assistance for health during 2000-13. ${ }^{37}$ Therefore, firm political commitment and adequate resources are now needed to put cost effective and feasible measures against non-communicable diseases into practice.

This study highlights the necessity for facilitating the speed of reduction in disability, ${ }^{5}$ while further pinpointing the main target diseases for realising this aim. At a global level, three diseases-namely diabetes, primary headache with medication overuse, and depressive disorders-are not only the most important negative factors for changes in $\mathrm{HALE}_{0}$ but also mainly or only affect population health through disability. Prevention and control of these diseases, which have been discussed above, ${ }^{44-46}$ will promote compression of morbidity. In addition, the signs of increasing morbidity in females call for a gender perspective in reducing disability.

Finally, the major contribution of this study is to quantify how a wide range of diseases and injuries influence changes in population health in term of $\mathrm{HALE}_{0}$, a summary measure of population health with several advantages over health gap measures and other health expectancy measures. On the basis of this contribution, our detailed country specific decomposition results will benefit the development of national health policies that take account of the substantial variations in the role of diseases and injuries in change in population health across countries.

We thank the Global Burden Disease Study 2013, which provides the data basis for this study. We thank Yue Zhang for her assistance in data analysis and Zhenjie Wang for his valuable comments on the first draft. HC especially appreciates the support from Tianguang Meng.

Contributors: $X Z$ and $Y G$ contributed equally to this paper and are joint corresponding authors. $\mathrm{HC}, \mathrm{GC}, \mathrm{XZ}$, and $\mathrm{YG}$ designed the study. $\mathrm{HC}$ was responsible for the data collection, literature review, and data analysis. $\mathrm{HC}$ and GC interpreted the data and prepared the first draft. $H C, G C, X Z$, and $Y G$ revised the draft. All authors had full access to all of the data (including statistical reports and tables) in the study and can take responsibility for the integrity of the data and the accuracy of the data analysis. The corresponding authors attest that all listed authors meet authorship criteria and that no others meeting the criteria have been omitted. XZ and $Y G$ are the guarantors.

Funding: This study was supported by the National Key R\&D Program of China (No 2018YFC2000603), National Natural Science Foundation of China (No 71403005), and Supportive Fund for Young Scholars of School of Public Health, Peking University. The funders had no role in study design, data collection, analysis, interpretation, or writing of the article. The corresponding authors had full access to all the data in the study and final responsibility for the decision to submit for publication. The authors were independent from the study sponsors.

Competing interests: All authors have completed the ICMJE uniform disclosure form at www.icmje.org/coi_disclosure.pdf (available on request from the corresponding authors) and declare: GC and HC received grants from the National Key R\&D Program of China; HC received grants from the National Natural Science Foundation of China and School of Public Health, Peking University; no financial relationships with any organisations that might have an interest in the submitted work in the previous three years; no other relationships or activities that could appear to have influenced the submitted work. Ethical approval: Not needed.

Data sharing: The full dataset in this study can be obtained from the Institute for Health Metrics and Evaluation (http://www.healthdata. org/). Both the statistical code and detailed region or country specific decomposition results of 306 diseases and injuries are available on request from $\mathrm{HC}$ at chenhe1984@bjmu.edu.cn.

Transparency: The lead authors affirm that the manuscript is an honest, accurate, and transparent account of the study being reported; that no important aspects of the study have been omitted; and that any discrepancies from the study as planned (and, if relevant, registered) have been explained.

This is an Open Access article distributed in accordance with the Creative Commons Attribution Non Commercial (CC BY-NC 4.0) license, which permits others to distribute, remix, adapt, build upon this work non-commercially, and license their derivative works on different terms, provided the original work is properly cited and the use is noncommercial. See: http://creativecommons.org/licenses/by-nc/4.0/.

1 Berthelot JM. Health-adjusted life expectancy (HALE). In: Robine J-M, Jagger C, Mathers CD, et al. eds. Determing Health Expectancy. Wiley, 2003: 235-61.

2 Robine JM, Cambois E, Nusselder W, Jeune B, Oyen HV, Jagger CJA: EHLEIS team. The joint action on healthy life years (JA: EHLEIS). Arch Public Health 2013;71:2. doi:10.1186/0778-7367-71-2

3 Jagger C, Gillies C, Moscone F, et al, EHLEIS team. Inequalities in healthy life years in the 25 countries of the European Union in 2005 a cross-national meta-regression analysis. Lancet 2008;372:212431. doi:10.1016/S0140-6736(08)61594-9

4 Salomon JA, Wang H, Freeman MK, et al. Healthy life expectancy for 187 countries, 1990-2010: a systematic analysis for the Global Burden Disease Study 2010. Lancet 2012;380:2144-62 doi:10.1016/S0140-6736(12)61690-0

5 Murray CJ, Barber RM, Foreman KJ, et al, GBD 2013 DALYs and HALE Collaborators. Global, regional, and national disability-adjusted life years (DALYs) for 306 diseases and injuries and healthy life expectancy (HALE) for 188 countries, 1990-2013: quantifying the epidemiological transition. Lancet 2015;386:2145-91. doi:10.1016/S0140-6736(15)61340-X

6 Brønnum-Hansen H, Duraidi M, Qalalwa K, Jeune B. Increasing disability-free life expectancy among older adults in Palestine from 2006 to 2010. Eur J Public Health 2015;25:335-9. doi:10.1093/ eurpub/cku069

7 Murray CJ, Salomon JA, Mathers C. A critical examination of summary measures of population health. Bull World Health Organ 2000;78:981-94.

8 Sullivan DF. A single index of mortality and morbidity. HSMHA Health Rep 1971;86:347-54. doi:10.2307/4594169

9 Jagger C, Robine JM. Healthy life expectancy. In: Rogers RG, Crimmins EM, eds. International Handbook of Adult Mortality. 1st ed. Springer, 2011: 551-68. doi:10.1007/978-90-481-9996-9_26

10 GBD 2013 Mortality and Causes of Death Collaborators. Global, regional, and national age-sex specific all-cause and cause-specific mortality for 240 causes of death, 1990-2013: a systematic analysis for the Global Burden of Disease Study 2013. Lancet 2015;385:11771. doi:10.1016/S0140-6736(14)61682-2

11 Salomon JA, Vos T, Hogan DR, et al. Common values in assessing health outcomes from disease and injury: disability weights measurement study for the Global Burden of Disease Study 2010. Lancet 2012;380:2129-43. doi:10.1016/S01406736(12)61680-8 
12 Van Oyen H, Nusselder W, Jagger C, Kolip P, Cambois E, Robine JM. Gender differences in healthy life years within the EU: an exploration of the "health-survival" paradox. Int I Public Health 2013;58:143-55. doi:10.1007/s00038-012-0361-1

13 Nusselder WJ, Looman CW. Decomposition of differences in health expectancy by cause. Demography 2004:41:315-34. doi:10.1353/ dem.2004.0017

14 Begg SJ. Health in a 'post-transition' Australia: adding years to life or life to years? Aust Health Rev 2014:38:1-5. doi:10.1071/AH13114

15 Banham D, Woollacott T, Lynch J. Healthy life gains in South Australia 1999-2008: analysis of a local Burden of Disease series. Popul Health Metr 2011:9:13. doi:10.1186/1478-7954-9-13

16 Global Burden of Disease Study 2013 Collaborators. Global, regional, and national incidence, prevalence, and years lived with disability for 301 acute and chronic diseases and injuries in 188 countries, 1990-2013: a systematic analysis for the Global Burden of Disease Study 2013. Lancet 2015;386:743-800. doi:10.1016/S01406736(15)60692-4

17 Murray CIL, Ezzati M, Flaxman AD, et al. GBD 2010: design, definitions, and metrics. Lancet 2012;380:2063-6. doi:10.1016 S0140-6736(12)61899-6

18 Murray CJ, Vos T, Lozano R, et al. Disability-adjusted life years (DALYS) for 291 diseases and injuries in 21 regions, 1990-2010: a systematic analysis for the Global Burden of Disease Study 2010. Lancet 2012;380:2197-223. doi:10.1016/S01406736(12)61689-4

19 Vos T, Flaxman AD, Naghavi M, et al. Years lived with disability (YLDs) for 1160 sequelae of 289 diseases and injuries 1990-2010: a systematic analysis for the Global Burden of Disease Study 2010. Lancet 2012;380:2163-96. doi:10.1016/ S0140-6736(12)61729-2

20 Arriaga EE. Measuring and explaining the change in life expectancies. Demography 1984:21:83-96. doi:10.2307/2061029

21 Arriaga EE. Changing trends in mortality decline during the last decades. In: Ruzicka L, Wunsch G, Kane P, eds. Differential Mortality: Methodological Issues and Biosocial Factors. Clarendon Press, 1989. 105-29.

22 Chen H, Wang H, Crimmins EM, Chen G, Huang C, Zheng X. The contributions of diseases to disability burden among the elderly population in China. J Aging Health 2014;26:261-82. doi:10.1177/0898264313514442

23 Van Oyen H, Charafeddine R, Deboosere P, et al. Contribution of mortality and disability to the secular trend in health inequality at the turn of century in Belgium. Eur J Public Health 2011;21:781-7. doi:10.1093/eurpub/ckq198

24 Amiel Y, Cowell FA. Thinking about Inequality. Cambridge University Press, 1999. doi:10.1017/CB09780511492266

25 Klijs B, Nusselder WJ, Looman CW, Mackenbach JP. Educational disparities in the burden of disability: contributions of disease prevalence and disabling impact. Am J Public Health 2014;104:e141-8. doi:10.2105/AJPH.2014.301924

26 Van Oyen $\mathrm{H}$, Berger $\mathrm{N}$, Nusselder W, et al. The effect of smoking on the duration of life with and without disability, Belgium 1997-2011. BMC Public Health 2014;14:723. doi:10.1186/1471-2458-14-723

27 Imai K, Soneji S. On the Estimation of Disability-Free Life Expectancy: Sullivan' Method and Its Extension. I Am Stat Assoc 2007;102:1199211. doi:10.1198/016214507000000040

28 McGrail K, Lavergne R, Lewis S. The chronic disease explosion: artificial bang or empirical whimper?BMJ 2016;352:i1312. doi:10.1136/bmj.i1312

29 Bots SH, Peters SAE, Woodward M. Sex differences in coronary heart disease and stroke mortality: a global assessment of the effect of ageing between 1980 and 2010. BMJ Glob Health 2017;2:e000298. doi:10.1136/bmjgh-2017-000298

30 Gordon SB, Bruce NG, Grigg J, et al. Respiratory risks from household air pollution in low and middle income countries. Lancet Respir Med 2014;2:823-60. doi:10.1016/S2213-2600(14)70168-7
31 Krishna B, Balakrishnan K, Siddiqui AR, Begum BA, Bachani D, Brauer M. Tackling the health burden of air pollution in South Asia. BMI 2017:359:j5209. doi:10.1136/bmj.j5209

32 GBD 2015 Maternal Mortality Collaborators. Global, regional, and national levels of maternal mortality, 1990-2015: a systematic analysis for the Global Burden of Disease Study 2015. Lancet 2016;388:1775-812. doi:10.1016/S01406736(16)31470-2

33 Cao B, Bray F, Beltrán-Sánchez H, Ginsburg O, Soneji S, Soerjomataram I. Benchmarking life expectancy and cancer mortality: global comparison with cardiovascular disease 1981-2010. BMJ 2017;357:j2765. doi:10.1136/bmj.j2765

34 Roth GA, Huffman MD, Moran AE, et al. Global and regional patterns in cardiovascular mortality from 1990 to 2013. Circulation 2015;132:1667-78. doi:10.1161/ CIRCULATIONAHA.114.008720

35 Hunter DJ, Reddy KS. Noncommunicable diseases. N Engl J Med 2013;369:1336-43. doi:10.1056/NEJMra1109345

36 Ezzati M, Riboli E. Behavioral and dietary risk factors for noncommunicable diseases. N Engl J Med 2013;369:954-64. doi:10.1056/NEJMra1203528

37 Dieleman JL, Schneider MT, Haakenstad A, et al. Development assistance for health: past trends, associations, and the future of international financial flows for health. Lancet 2016;387:2536-44. doi:10.1016/S0140-6736(16)30168-4

38 Murray CJ, Rosenfeld LC, Lim SS, et al. Global malaria mortality between 1980 and 2010: a systematic analysis Lancet 2012;379:413-31. doi:10.1016/S0140-6736(12)60034-8

39 Dhamoon MS, Moon YP, Paik MC, et al. Long-term functional recovery after first ischemic stroke: the Northern Manhattan Study. Stroke 2009;40:2805-11. doi:10.1161/STROKEAHA.109.549576

40 Vartiainen E, Laatikainen T, Peltonen M, et al. Thirty-five-year trends in cardiovascular risk factors in Finland. Int I Epidemiol 2010;39:504 18. doi:10.1093/ije/dyp330

41 Puska P, Vartiainen E, Laatikainen T, et al. eds. The North Karelia Project: From North Karelia to National Action. Helsinki University Printing House, 2009.

42 Hogan DR, Baltussen R, Hayashi C, Lauer JA, Salomon JA. Cost effectiveness analysis of strategies to combat HIV/AIDS in developing countries. BMJ 2005;331:1431-7. doi:10.1136/ bmj.38643.368692.68

43 Lundgren JD, Babiker AG, Gordin F, et al, INSIGHT START Study Group. Initiation of Antiretroviral Therapy in Early Asymptomatic HIV Infection. N Engl / Med 2015;373:795-807. doi:10.1056/ NEJMoa1506816

44 World Health Organization. Tackling NCDs: 'Best Buys' and Other Recommended Interventions for the Prevention and Control of Noncommunicable Diseases. WHO, 2017

45 Drug and Therapeutics Bulletin. Management of medication overuse headache. BMJ 2010;340:c1305. doi:10.1136/bmi.c1305

46 World Health Organization. mhGAP Intervention Guide for Mental, Neurological and Substance Use Disorders in Non-specialized Health Settings: version 2.0. WHO, 2016.

47 Levey AS, Coresh J, Balk E, et al, National Kidney Foundation. National Kidney Foundation practice guidelines for chronic kidney disease: evaluation, classification, and stratification. Ann Intern Med 2003;139:137-47. doi:10.7326/0003-4819-139-2200307150-00013

48 Luttmann A, Jäger M, Griefahn B, et al. Protecting Workers' Health Series No. 5. Preventing Musculoskeletal Disorders in the Workplace. World Health Organization, 2003.

49 Health and Safety Executive for Northern Ireland, Health and Safety Authority. Guidance on the Prevention and Management of Musculoskeletal Disorders (MSDs) in the Workplace. HSENI and HSA, 2013.

Web appendix: Appendix A-D 